\title{
EDITORIAL
}

\section{European curriculum recommendations for training in adult respiratory medicine: crossing boundaries with HERMES}

\author{
R. Loddenkemper*, T. Séverin ${ }^{\#}$ and P.L. Haslam
}

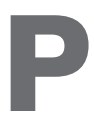

reventing, curing or alleviating suffering from respiratory diseases has always been part of the European Respiratory Society's (ERS) mission. In that respect, promoting and providing state-of-the-art medical education, in order to achieve the highest possible standards of practice in respiratory medicine and to improve harmonisation of training across Europe, is a major priority for the ERS.

In 2005, in order to support these ambitious objectives, the ERS School established the HERMES initiative (Harmonisation of Education in Respiratory Medicine for European Specialists). The aim of the first project under this initiative was to improve the harmonisation of training in adult respiratory medicine across Europe. This project was led by a Task Force of 13 international experts. The first phase of the project, undertaken during 2005 and 2006, was to obtain a Europe-wide consensus to develop a European core syllabus for training in adult respiratory medicine. The syllabus was produced and published in 2006 by the HERMES Task Force [1, 2].

The extensive coverage that was dedicated to the 2006 syllabus throughout Europe certainly confirmed the merit and validity of the initiative. A survey performed across 18 countries in December 2007 revealed that seven countries had already proceeded to implementation, one was undergoing implementation and the remaining 10 countries already had plans of implementation in place. In addition, the syllabus is available on the ERS website in 24 languages and has been published in several national publications and on various national society websites [3-5]. The syllabus has also been presented and discussed at 14 national and regional congresses.

Between 2006 and 2008, the HERMES Task Force moved on to the second phase of the project. The aim was to add to the syllabus by producing consensus recommendations for the development of a full European curriculum for training in adult respiratory medicine. The curriculum recommendations were published recently in a second report from the HERMES Task Force [6]. The

\footnotetext{
*Pneumology II, Chest Clinic Heckeshorn, Berlin, Germany. "European Respiratory Society Headquarters, Lausanne, Switzerland. "Cell Biology Unit, National Heart and Lung Institute, London, UK.
}

STATEMENT OF INTEREST: None declared

CORRESPONDENCE: R. Loddenkemper, Pneumology II, Chest Clinic Heckeshorn, Zum Heckeshorn 33, Berlin, D-14109, Germany. Fax: 49 3980022286; E-mail: rloddenkemper@dzk-tuberkulose.de two documents have a different, yet complementary focus. The syllabus published in 2006 listed all the topics that general respiratory specialists should have knowledge of and also the levels of knowledge and clinical competence specialists should have achieved by the time they qualify as general respiratory medicine specialists. Thus, the syllabus was mostly concerned with what topics need to be covered in a training programme. In addition, the latest curriculum document recommends how these topics and all the additional attributes required for daily clinical practice could be taught, assessed and learnt. The two documents are intended to be used together.

\section{STRUCTURE OF THE CURRICULUM DOCUMENT}

In an attempt to account for the needs and interests of a wide readership, the Task Force report on the European curriculum for training in adult respiratory medicine [6] has been split into two distinct parts: 1) the curriculum rationale, which includes broad-based, quite theoretical, considerations and recommendations; and 2) the curriculum modules, which list core clinical competencies.

The curriculum rationale is arranged under the following headings: 1) the clinical field of respiratory medicine; 2) principles underpinning the development of a curriculum for respiratory medicine; 3 ) the education of respiratory medicine trainees; 4) assessment; 5) the characteristics and responsibilities of key training personnel; 6) accountability and regulation; and 7) quality assurance, validation, accreditation and evaluation of the programme.

The curriculum modules are structured into 34 clinical modules covering the majority of topics listed in the syllabus. However, the modules have been reorganised into essentially disease-based and other clinically oriented groups to better match training within a clinical setting. Curriculum developers, trainers and trainees should also refer to the complementary syllabus document, which lists additional knowledge-based competencies that trainees need to acquire, e.g. knowledge of respiratory structure and function, associated fields relevant to adult respiratory medicine and additional core generic abilities. Each of the 34 curriculum modules contains information pertaining to: 1) knowledge; 2) skills; 3) attitudes and behaviours; and 4) existing guidelines.

Matching existing guidelines with each clinical module proved a very enriching exercise, enabling the Task Force to identify 
gaps that will need to be filled. For instance, no relevant guidelines could be identified for lung transplantation, palliative care or imaging techniques, while very few resources could be identified for topics such as cystic fibrosis and interstitial lung diseases. Together with providing different types of learning materials pertaining to the different topics listed in both syllabus and curriculum recommendations, filling the gaps identified by the Task Force will be the task of the ERS School and the ERS Guidelines Director over the next few years.

\section{METHODOLOGY}

The curriculum rationale was developed after intensive preliminary discussions by the HERMES Task Force, followed by initial drafting by professional educational advisors to the Task Force, C. Coles (Faculty of Education, University of Winchester, Winchester, UK) and G.D. Phillips (Dorset County Hospital Foundation Trust, Dorchester, UK), with input from the Task Force Chair, R. Loddenkemper, and Task Force CoChair and ERS School Chair, P.L. Haslam. It was then reviewed by all the members of the Task Force and amended to achieve final consensus.

The curriculum modules were developed through a similar procedure. Each module was initially drafted by individual members of the Task Force or by invited collaborating experts. Those modules were then grouped into 10 different surveys and submitted to the international respiratory community via an online Delphi-consensus review process. The different groups of modules were reviewed by between 15 and 118 experts. The feedback was then discussed during a meeting on December 15, 2007, which was attended by 30 Task Force members and national respondents, to achieve the final consensus.

\section{CHALLENGES FACED}

\section{To whom are we talking?}

One of the main challenges the Task force faced while drafting the curriculum recommendations was to account for the requirements of a wide readership with different interests and needs. Those identified as potential readers included, among others, the following. 1) Policy makers who might not be professionals in the field. This group was felt to be likely to seek broad-based background information and guidance pertaining to the scope of training in respiratory medicine, as well as to the roles and responsibilities of respiratory physicians. 2) Curriculum developers and supervisors who are responsible for the development of curricula for respiratory medicine specialists, or for supervising the implementation at national, regional or even local level. This group was felt to be likely to seek more concrete guidance with regard to the content and structure of a good training programme. 3) Educational and clinical supervisors who are in daily contact with respiratory medicine trainees. This group was felt to be more likely to seek practical advice as to what and how they should teach their trainees, and how they should supervise and assess them. 4) Trainees undergoing postgraduate training as specialists in respiratory medicine. This group was felt to be most likely to seek very practical information as to what the exact scope of their activities would include once they are qualified, as well as to their own learning requirements, in particular regarding preparation for assessment.

\section{Shall we go European, national or local?}

National, regional and local circumstances, such as the overall organisation of postgraduate medical training, the infrastructure available, the size of the programme, etc., have a crucial impact on the way training is actually delivered.

Therefore, it is recognised that the final model of each training programme is the responsibility of each individual country and that European recommendations can't go into any national or local specificities. Nevertheless, it is hoped that the work of the Task Force will encourage all European countries to review their curricula for education and training in respiratory medicine on the basis of the recommendations provided, as occurred with the syllabus in many countries. The HERMES curriculum rationale and modules will certainly prove to be a valuable resource for drafting such country- and readerspecific documents.

It should also be emphasised that the aim of the Task Force, while drafting the curriculum document, has been to strive for the highest possible standards of education and training, with the final benefit being for the patients. As with the syllabus, it is recognised that not all countries may immediately be able to achieve the levels of practice set out in the document, but it is hoped that all countries will see this as their ultimate aim in the long term.

\section{Shall we prescribe, recommend or remain silent?}

As stated previously, it is recognised that the practical modalities of the way training is organised and delivered is not within the realm of the Task Force; therefore, being prescriptive was felt to be inappropriate. However, it was felt that it was the responsibility of the Task Force to provide some clear recommendations. For instance, recommendations pertaining to overall training duration and structure are clearly explained in the document, and it is hoped that these recommendations will be implemented throughout Europe.

However, on another controversial issue, the Task Force decided to refrain from providing any recommendation with regard to minimum numbers of procedures to be performed to become qualified. A study performed in 2008 among all participating countries revealed that many countries had no specifications and that there were huge discrepancies among those which had specified numbers. For most procedures listed in the syllabus, figures ranged from less than 10 to more than 100. On one hand, this seemed to indicate a need for guidance and harmonisation. On the other hand, it was felt that while some very skilled trainees might become competent very quickly, some others might need much more hands-on experience than stated in any standard recommendation. Therefore, it was felt that the decision of whether or not a trainee is competent to perform a given procedure should be left to the clinical trainer/supervisor after in situ observation/assessment (subject to any local minimum legal training requirement).

\section{LOOKING TO THE FUTURE: EUROPEAN EXAMINATION AND ACCREDITATION OF TRAINING CENTRES}

In parallel with the development of these curriculum recommendations, the HERMES Task Force and the ERS School have worked hard in preparing the first European examination in adult respiratory medicine. This first examination will take place 
on October 4, 2008, in Berlin at the ERS Annual Congress. The exam will be based on the topics and levels of knowledge/ competence listed in the 2006 syllabus and will be composed of 90 multiple-choice questions [7]. To date, candidates from more than 20 European and non-European countries have already registered, once again proving the merit of the initiative. It is hoped that in the future, this examination will become a cornerstone towards harmonisation of knowledge across Europe and beyond. It is also hoped that it will be internationally recognised as a sign of state-of-the-art, up-to-date knowledge. Therefore, the Task Force would like to strongly encourage the international respiratory community to take this examination and repeat it at 5-10-yr intervals in order to keep knowledge up-to-date.

Finally, the last challenge for the Task Force will be to provide a solid basis for the accreditation of training centres in Europe. However, experience among other specialties has shown that this is by far the most difficult and costly undertaking. Methodology for this final step has, therefore, still not been defined. Meanwhile, the ERS School is now supporting expansion of the HERMES initiative into other areas of respiratory medicine. A paediatric HERMES Task Force has been established to produce a European syllabus and updated curriculum for training in paediatric respiratory medicine, and similar undertakings are being prepared for training in respiratory physiotherapy, as well as for spirometry training (e.g. the European Spirometry Driving License).

In conclusion, we encourage use of the new curriculum recommendations and the HERMES Task Force is happy to report that the HERMES initiative is definitely playing a very active and positive part in helping members from the international respiratory community to cross boundaries.

\section{REFERENCES}

1 Loddenkemper R, Séverin T, Eiselé J-L, et al. HERMES: a European core syllabus in respiratory medicine. Breathe 2006; 3: 59-70.

2 Loddenkemper R, Séverin T, Eiselé J-L, Haslam PL. HERMES: good reasons for harmonising education and training in respiratory medicine. Eur Respir J 2006; 28: 470-471.

3 Loddenkemper R, Séverin T, Eiselé J-L, et al. HERMES: a European core syllabus in respiratory medicine. Multidisciplinary Respiratory Medicine 2006; 3: 19-29.

4 Bendra Europos suaugusiưự pulmonologụ rezidentūros programa (HERMES projektas). [European Harmonised adult pulmonology residence programme (HERMES project)]. Vaiku pulmonologija ir alergologija 2007; 10: 3703-3712.

5 Appendix to the UK Respiratary Medicine Curriculum. UK Respiratory Specialist Training Committee (SAC) on behalf of the Joint Royal College of Physicians Training Board (JRCPTB). Available from www.jrcptb.org.uk/Pages/default.aspx.

6 Loddenkemper R, Haslam PL, Séverin T, et al. European Curriculum for Training in Adult Respiratory Medicine: 2nd Report of the ERS HERMES Task Force. Breathe 2008; (in press).

7 Loddenkemper R, Haslam PL. Multiple choice and the only answer: the HERMES examination. Breathe 2008; 4: 242-248. 